\title{
Dimensão política da Comunicação Científica: perspectivas teórico-epistemológicas
}

\author{
Tiago Santos Sampaio \\ Ana Maria Ferreira Menezes ${ }^{2}$ \\ Alfredo Eurico Rodrigues Matta ${ }^{3}$
}

Resumo: O desenvolvimento da Ciência, Tecnologia e Inovação (C,T\&I), no contexto da sociedade em rede ${ }_{2}$ exige a compreensão sobre a Comunicação Científica para além da sua dimensão técnica e como um relevante requisito para a cidadania. Diante disso, este artigo objetiva discutir as bases teóricoepistemológicas que sustentam o entendimento da Comunicação Científica como uma forma de promover a democratização e a ampla participação dos sujeitos nos processos de produção e difusão do conhecimento científico. Por meio de revisão conceitual e discussão teórica, propõe valorizar a dimensão política da Comunicação Científica de modo a condicionar a sua efetividade como decorrência de processos dialógicos que atuem, concomitantemente, para aprimorar a interação dos especialistas e destes com o "público leigo". Os resultados de tal percurso são: as contribuições teóricas voltadas à discussão da Comunicação Científica, uma síntese dialética da disseminação e divulgação, à luz do conceito de arenas trans-epistêmicas; o destaque dos aportes conceituais de esfera pública em Hannah Arendt e Habermas, uma forma de reforçar os princípios que subsidiam a noção de Comunicação Pública da Ciência.

Palavras-chave: Arenas transepistêmicas. Comunicação Científica. Comunicação pública da ciência. C,T\&I. Esfera pública.

Abstract: The development of Science, Technology and Innovation (C, T \& I) in the context of the network society has required the understanding of scientific communication beyond its technical dimension and as a relevant requirement for citizenship. Therefore, this article aims to discuss the theoretical-epistemological bases that support the understanding of Scientific Communication as a way of promoting the democratization and broad participation of the subjects in the processes of production and diffusion of scientific knowledge. Through a conceptual revision and theoretical discussion, it is proposed to value the political dimension of scientific communication in order to condition its effectiveness as a result of dialogic processes that act, simultaneously, to improve the interaction between the specialists and of these with the "lay public" . The course followed has as a result theoretical contributions focused on the discussion of scientific communication as a dialectical synthesis of dissemination and dissemination, in light of the concept of trans-epistemic arenas; and to highlight the conceptual contributions of the public sphere in Hannah Arendt and Habermas as a way of reinforcing the principles that subsidize the notion of public communication of science.

Keywords: Transepistemic arenas. Scientific Communication. Public communication of science. C, T \& I. Public sphere.

\footnotetext{
${ }^{1}$ Doutorando pelo Programa Doutorado Multi-institucional e Multidisciplinar em Difusão do Conhecimento (DMMDC) (UFBA, UNEB, UEFS, IFBA, SENAI-CIMATEC e LNCC). Mestre em Cultura e Sociedade pela Universidade Federal da Bahia (UFBA). Docente do Curso de Comunicação Social da Universidade do Estado da Bahia (UNEB), Campus XIV, Conceição do Coité. Membro do Grupo de Pesquisa Acompanhamento e Avaliação de Políticas Públicas (AAPP) da UNEB. E-mail: tssampaio1@hotmail.com.

2 Doutora em Administração Pública pela Universidade Federal da Bahia (UFBA). Mestra em Economia pela UFBA. Professora da Universidade do Estado da Bahia (UNEB), Coordenadora do Curso de Especialização em Gestão Pública Municipal, na modalidade a distância (bolsista CAPES) e Professora permanente do Doutorado Multiinstitucional, Multidisciplinar em Difusão do Conhecimento.E-mail: ana mmenezes@hotmail.com.

${ }^{3}$ Doutor em Educação pela Universidade Federal da Bahia/Université Laval (Canadá). Pós-Doutorado na Universidade do Porto em Educação a Distância e Comunidades de Aprendizagem Internacionais em Língua Portuguesa. Mestre em História pela (UFBA). Professor do Doutorado Interinstitucional Multidisciplinar em Difusão do Conhecimento, Professor do Programa de Pós-Graduação em Educação e Contemporaneidades. E-mail: alfredo@matta.pro.br.
} 


\section{A C,T\&I e a comunicação no contexto da sociedade em rede}

A reflexão sobre o desenvolvimento da Ciência, Tecnologia e Inovação (C,T\&I) e seus impactos e influências no tecido social tem sido conduzida por vieses teóricos que enfatizam diferentes questões referentes à ordem econômica, cultural, social ou da sua própria evolução técnica. Entre as perspectivas teóricas existentes, a de sociedade em rede, desenvolvida por Castells (2016), apresenta como uma das linhas condutoras de análise a centralidade da informação e do conhecimento, mediante verificação das condições que engendraram esse status, que se converteu no leitmotiv de novas e constantes transformações.

Castells contextualiza a revolução tecnológica, situando-a no todo social e não como resultante da emergência de processos apenas técnicos. Por isso, afirma que o que caracteriza esse cenário não é, exatamente, a centralidade do conhecimento e da informação por si, mas as suas aplicações "para a geração de conhecimentos e dispositivos de processamento/comunicação da informação, em um ciclo de realimentação cumulativo entre a inovação e seu uso" (CASTELLS, 2016, p. 88).

O lugar da comunicação na interpretação da sociedade não aparece restrito ao desenvolvimento dos dispositivos tecnológicos, mas a todo o conjunto de relações envolvidas na produção de conhecimento, logo, no conjunto de uma série de variáveis sociais, culturais, econômicas e políticas. Essa afirmação demarca o papel do contexto na qualidade de elemento de ordem epistemológica escolhido para orientar o cumprimento do objetivo deste texto, qual seja, discutir a Comunicação Científica, valorizando a sua dimensão política presente nas possibilidades de promover a democratização e a ampla participação dos sujeitos nos processos de produção e difusão do conhecimento científico.

Essa escolha se justifica à medida que compreendemos a Comunicação Científica como decorrência do desenvolvimento da C,T\&I, parte do contexto da sociedade em rede. Para demarcar a Comunicação Científica na condição de campo do conhecimento ${ }^{4}$ que pode atuar teórica e politicamente, contribuindo para a cidadania, é preciso compreendê-la não somente em sua dimensão técnica, mas imersa na teia de relações sociais configurada pelo contexto discutido. Assim, entendemos que a concretização desse requisito se torna viável ao considerarmos como unidade conceitual balizadora do contexto a ideia de sociedade em rede, por meio da qual, os processos comunicacionais, incluindo os de base científica, são interpretados pelo olhar que vai além da ideia de progresso técnico como fim em si mesmo e, exclusivamente, como evolução de dispositivos e procedimentos operacionais.

Ancorados nessa concepção, reafirmamos, os processos comunicacionais decorrem, também, de dinâmicas interativas dos sujeitos que partilham, em rede, seus conhecimentos, cuja relevância deve ser vista pelo prisma contextual e não de uma hierarquização que busca mensurar e valorar conhecimentos

\footnotetext{
${ }^{4}$ Utilizamos essa nomenclatura em alinhamento com o conceito de campo científico de Bourdieu (2004). O autor define campo científico como um espaço de concorrência estruturada e, ao mesmo tempo, de integração social por meio da qual agentes atuam em torno de interesses e competências específicas. Essa estrutura se configura por relações de força que orientam as ações e estratégias de cada um no campo.
} 
nos moldes do capital. No que se refere à Comunicação Científica, significa condicionar a sua efetividade como resultante de processos dialógicos e plurais que atuem, ao mesmo tempo, para aprimorar a interação dos especialistas e destes com o "público leigo", reconhecendo o papel destes na produção de conhecimentos inovadores.

Para cumprir com a proposta deste texto, propomos, por meio de revisão conceitual e discussão teórica, valorizar a dimensão política da Comunicação Científica, estabelecendo o seguinte percurso e premissas norteadoras: a Comunicação Científica como síntese dialética dos processos de disseminação e divulgação, logo, efeito das interações nas arenas trans-epistêmicas (KNORR CETTINA, 1996; 2005) e a noção de Comunicação Pública da Ciência imbuída de princípios como pluralidade e participação na esfera pública, preconizada por Hannah Arendt (2015), Habermas (2003; 2012).

\section{Comunicação Científica como síntese dialética e arenas transepistêmicas}

Considerando a emergência da C,T\&I no contexto da sociedade em rede, preconizada por Castells (2016), que condiciona a necessidade da sua publicização, repertoriamos alguns conceitos que delimitam o campo da Comunicação Científica, de modo a definir a sua atuação e objetivos. Leite (2006) afirma que, desde o início, a Ciência da Informação se dedica à compreensão dos processos de informação no âmbito científico, o que inclui desde a utilização de métodos bibliométricos à utilização das tecnologias da comunicação por membros da comunidade científica para publicização e discussão de resultados de pesquisas. Assim sendo, a Comunicação Científica integra o próprio desenvolvimento da C,T\&I, uma vez que, em conformidade com o que aponta Meadows (1999), este também se refere a um conjunto de conhecimentos de caráter público, tendo a mesma importância que procedimentos intrínsecos ao fazer científico ordinário como coleta, análise e avaliação de dados.

Segundo Caribé (2015), o termo Comunicação Científica é bastante genérico e engloba outros vistos como processos que se diferenciam por critérios ligados a tipos de públicos e modos específicos de socialização de informações, tais quais difusão científica, divulgação científica, popularização da ciência, disseminação cientifica etc. De modo geral, relaciona-se às "atividades desenvolvidas por diferentes pessoas e instituições, com o objetivo de levar a informação científica a determinado grupo social” (CARIBÉ, 2015, p. 90). Segundo a autora, o termo tem autoria imputada a John Desmond Bernal, na obra A função social da ciência (1939), para se referir às atividades referentes à produção, disseminação e uso da informação desde a concepção das ideias pelos cientistas até o reconhecimento destas como parte de um estoque de conhecimentos, reconhecidos e legitimados como científicos pelos pares. Tal aspecto aponta para uma série de variáveis na construção do conhecimento científico, as quais extravasam o campo da comunicação, para mostrar a ciência imersa em um complexo contexto de relações, cujas tensões são 
motivadas pela dinâmica de formação de consensos mínimos e reconhecimentos inerentes às legitimações próprias à composição de um capital científico, em alinhamento com o conceito de campo científico em Bourdieu (2004).

Bueno (2010), um dos maiores pesquisadores dessa temática no Brasil, afirma que a literatura brasileira não tem contribuído para o refinamento conceitual que dê suporte à teoria e à prática da Comunicação Científica, o que dificulta o estabelecimento dos limites da sua abrangência e atuação. Diferentemente de Caribé, Bueno, ao lado de diversos autores, restringe a Comunicação Científica a todas as formas de difundir a ciência entre os pares da comunidade científica, isto é, à transferência de informações científicas, tecnológicas ou associadas a inovações e que se destinam aos especialistas em determinadas áreas do conhecimento. Equipara-a, desse modo, ao termo disseminação científica. Por outro lado, define a divulgação científica como "a utilização de recursos, técnicas, processos e produtos (veículos ou canais) para a veiculação de informações científicas, tecnológicas ou associadas a inovações ao público leigo" (BUENO, 2009, p.162).

De acordo com essa concepção, o termo difusão cientifica refere-se a uma expressão mais genérica da qual deriva a disseminação e a divulgação. Segundo Bueno,

A difusão científica é todo e qualquer processo ou recurso utilizado na veiculação de informações científicas e tecnológicas, como o envio de mensagens elaboradas em códigos ou linguagens universalmente compreensíveis à totalidade do universo receptor disponível, em determinada unidade geográfica, sociopolítica ou cultural. Esse termo genérico engloba todos os tipos de comunicação de informação científica e tecnológica. A difusão é subdividida em dois níveis, de acordo com a linguagem e o público ao qual se destina. Assim, existe a difusão para cientistas, denominada disseminação da ciência, e existe a difusão para o público em geral, denominada divulgação científica. (BUENO, 1984, p. 34).

Tão genérico quanto Comunicação Científica, o termo difusão cientifica abrange diversos formatos de tornar públicas as informações da ciência como periódicos especializados, sistemas de informação, banco de dados, mas ainda congressos, simpósios, seminários e reuniões científicas, de forma geral. Também compreende equipamentos culturais tais quais museus, exposições, bem como a utilização de veículos da mídia de massa, jornais e programas de rádio e TV.

No âmbito da disseminação, a transferência da informação ocorre por meio de códigos especializados e linguagem técnica, direcionando as mensagens a um público seleto, composto de especialistas aptos à decodificação e à interação em uma comunicação classificada com horizontal (CARIBÉ, 2015). A autora lembra que, nesta, as mensagens podem se reportar a dois níveis: a) intrapares: quando se direciona a um conteúdo e a um código fechado, limitando o público interessado; b) extrapares: 
quando se direciona a especialistas fora do objeto da comunicação, logo, um público multidisciplinar, com interesse científico mais diversificado, a depender da circunstância.

No caso da divulgação, Caribé (2015) explica, com base no dicionário Houaiss (2010), etimologicamente, os termos "divulgação e vulgarização são formados pelo antepositivo vulg, do latim, que significa povo, plebe, o qual apareceu em vocábulos de origem latina como vulgar, vulgo e vulgívago, a partir do século XIV" (2015, p. 169). Somente a partir do século XIX apareceriam os termos derivativos divulgar, divulgação, invulgar etc.

Cabe-nos agora ampliar esse entendimento para além das suas dimensões técnicas, problematizando o conceito de Comunicação Científica no que se refere à delimitação dessa atividade por público, uma forma de estabelecer níveis de cognição e eventuais hierarquias entre públicos tomando, para isso, o conhecimento como métrica. Diante da dicotomia entre os conceitos de disseminação e divulgação, consideramos que não se trata apenas de uma diferenciação expressa na superfície das nomenclaturas, mas que, por meio destas, reflete escolhas de ordem política. Optamos por adotar o termo Comunicação Científica, não como sinônimo da disseminação, e no lugar da difusão, não somente por este ser igualmente genérico, mas pelas possibilidades semânticas que o conceito de comunicação permite, quanto a um posicionamento mais próximo ao ideal de democratização do conhecimento científico.

O termo difusão sugere um sentido uniderecional de envio das mensagens, inclusive com a hierarquização destas em níveis relacionados aos públicos. Dentro desse espectro, existem outras classificações que acolhem significações referentes a nichos de especialistas, reforçando a endogenia na produção do conhecimento, logo, maior hermetismo e esoterismo. O termo comunicação traz em si a possibilidade, ainda que por vezes implícita, da dialogicidade e de algum nível de participação. Entendemos que a associação do termo disseminação como sinônimo da Comunicação Científica, em oposição à divulgação, sobre a qual não se cria essa mesma associação, confere à disseminação a ideia de maior completude, uma vez que os pares seriam, em tese, mais capazes ao diálogo. Ao "público leigo" caberia o lugar da recepção de mensagens previamente codificadas em outro nível de discurso. De acordo com tal concepção, os processos de apropriação, interação e participação, observáveis nessa categoria de público, tendem a ser vistos pelo prisma da retórica, para otimizar o seu entendimento e apreensão, válidos do ponto de vista de quem recebe e decodifica as mensagens, mas não de quem participa dos processos de construção do conhecimento científico, ainda que no lugar de eventuais consultas.

Esse posicionamento tem, em primeiro lugar, um amparo etimológico. Ao discutir o termo comunicação, Martino (2010) explica que, de raiz latina, a palavra communicatio significa "estar encarregado de" (munis); "atividade realizada conjuntamente" (co) e "reforço da ideia de atividade" (tio). Após explorar a etimologia em sua evolução histórica, conclui, apresentando os três sentidos que implicados: “1) o termo comunicação não designa todo e qualquer tipo de relação, mas aquela em que haja elementos que 
se destacam de um fundo de isolamento; 2) a intenção de romper o isolamento; 3) a ideia de uma realização em comum” (MARTINO, 2010, p. 13).

Ademais, a evolução das teorias da comunicação evidencia o percurso da concepção dos processos comunicacionais que se deslocou de modelos mecanicistas, em que se valorizavam a unidade e os fluxos de informação, em termos entrópicos e de paralelismos com mecanismos físicos, para proposições de ordem contextual, que consideram fatores sociais, psicológicos, históricos, culturais etc. Nestes últimos, a ideia de comunicação, face a face, ou mediada massivamente, não mais se assenta na visão diádica de emissor e receptor, que apenas recebe a informação e fornece um feedback. Passa-se à valorização de leituras interpretativas, em que os sujeitos são social e historicamente construídos e aptos à apropriação e à negociação dos sentidos das mensagens por meio de processos cognitivos complexos.

Dessa forma, dizer Comunicação Científica significa pôr em diálogo e em relação todos os sujeitos implicados na concepção das ideias científicas e na construção da ciência como um campo voltado para o atendimento de demandas sociais concretas. Trata-se de um posicionamento político, pois entendemos que, enquanto o termo Comunicação Científica, e consequentemente, as suas ações, se dirigirem a apenas uma parte da sociedade, hierarquizada sobre as outras pelo domínio de um conhecimento específico e valorizado, estabelece-se uma comunicação parcial e politicamente orientada a aprofundar distinções sociais, tendo o uso do conhecimento como critério de exclusão.

Desse modo, propomos, para viabilizar a completude da sua potência, o que quer dizer não somente manter as pessoas informadas, mas democratizar os processos de construção do conhecimento científico, no âmbito da sua discussão ampliada, a Comunicação Científica deve manifestar-se como uma sintese dialética da disseminação e da divulgação ${ }^{5}$. Deve também atuar com vistas a atender, de imediato, ao seu público. Isso não significa não reconhecer os contextos, as diferenças culturais, de formação de repertório, logo, as decorrentes e necessárias adaptações em formatos e linguagens, visando a melhor forma de comunicar, mas assumir o compromisso de informar a todos os públicos, sem estabelecer diferenças que deem margem a hierarquizações de conhecimentos.

Entendemos, assim, que a delimitação do conceito da Comunicação Científica se completa, sobretudo, porque se volta para diversos públicos, vislumbrando os seus diferentes repertórios culturais como elementos que agregam à construção do conhecimento científico novos desafios para

\footnotetext{
${ }^{5}$ A nomenclatura "síntese dialética", empregada para definir uma normatividade para a Comunicação Científica, inspira-se em Nonaka e Takeuchi (2008), os quais afirmam que o conhecimento é formado, concomitantemente, pelas dimensões explícitas e tácitas. Eles propõem uma Gestão do Conhecimento como síntese dialética, evidenciando que o reconhecimento, por parte das organizações, da dimensão tácita e a sua incorporação à criação e difusão do conhecimento explícito são fundamentais para otimizar os processos produtivos. De forma análoga, a Comunicação Científica deve ensejar as condições de valorização dos conhecimentos tanto do chamado público leigo quanto daqueles advindos dos especialistas, de modo a oportunizar uma ciência mais contextual, acessível e de caráter reconhecidamente público por se voltar às questões da sociedade.
} 
aprimoramento das suas formas de comunicar. Isso vai além da melhor organização sintática e semântica das mensagens, para concebê-las da mesma forma que um desdobramento da ideia de conhecimento como construção coletiva, uma síntese dialética de conhecimentos que partem de diversas fontes.

Essa concepção da Comunicação Científica envolve não somente uma série de variáveis de ordem técnica, mas também de orientações referentes ao cumprimento de outros objetivos organizacionais que não sejam apenas aqueles voltados para a melhoria de técnicas com o fim de potencialização dos lucros. Um primeiro passo, para tanto, refere-se ao reconhecimento da diversidade de públicos envolvidos no contexto da gestão do conhecimento científico e que reflete uma multiplicidade de interesses e questões próprias ao desenvolvimento da C,T\&I.

A argumentação que enfatiza a pluralidade como marca definidora dos públicos, aos quais a Comunicação Científica diz respeito, certamente é ampliada com o conceito de arenas transepistêmicas forjado por Knorr Cetina (1996; 2005). A necessidade de considerar outros públicos nas relações de construção do conhecimento científico, além daquelas restritas aos cientistas, não decorre somente de uma motivação política. Diversas outras relações influenciam esse processo e, consequentemente, as suas formas de comunicar. Ao denominar o cenário de tais interações como a organização contextual da ação científica, a autora declara que estas ocorrem permeadas de tensões e propõe o termo arenas transepistêmicas para colocar o cientista no contexto social em que se intercambiam recursos de diversas ordens que definem o capital científico. Dessa forma, a autora critica a noção de comunidade de especialistas, pois tal ideia reforça o imaginário dos cientistas isolados e inseridos em relações apenas entre os seus pares.

De acordo com Knorr Cettina (1996):

Así como no hay ninguna razón para creer que las interacciones entre los miembros de un grupo de especialidad sean puramente "cognitivas", tampoco hay razón para creer que las interacciones entre los miembros de una especialidad y otros científicos o nocientíficos se limiten a transferencias de dinero u otros intercambios comúnmente categorizados como "sociales". [...] Mi argumento es que si no podemos presumir que las elecciones "cognitivas" o "técnicas" del trabajo científico están exclusivamente determinadas por el grupo de pertenencia a una especialidad de un científico, no tiene sentido buscar una "comunidad de especialidad" como el contexto relevante para la producción de conocimiento. (1996, p. 151).

Essa proposição contextualiza a produção do conhecimento científico, evitando interpretações puristas e hierarquizadas da imagem do cientista em relação à sociedade e a projeta para o cotidiano das relações, inclusive para mostrar circunstâncias, descontinuidades, equívocos e trocas de recursos, além do monetário, presentes na rotina do fazer científico (KNORR CETTINA, 2005). 
Isso implica considerar, em conformidade com Bueno (2010), que, tanto na disseminação quanto na divulgação, as informações estão submetidas a uma série de constrangimentos, diversas vezes condicionados por questões fora do âmbito da C,T\&I. Segundo o autor, interesses extracientíficos, como os comerciais, políticos, militares e outros "estão, quase sempre, presentes na comunicação e na divulgação da ciência e tecnologia para resguardar privilégios de grupos (empresas ou governos) ou mesmo ambições pessoais" (BUENO, 2010, p. 6). Essa perspectiva impõe pensarmos o público para além de critérios que o definem como especialistas e leigos, uma vez que não estão em jogo apenas variáveis de ordens cognitivas ou de acesso ao conhecimento, mas também aquelas que o caracterizam por interesses econômicos, políticos, culturais etc.

Assim, a ideia de arenas transepistêmicas representa uma contribuição relevante para ampliar o espectro de público, considerando, por exemplo, agências de financiamento, universidades, empresas, órgão e agentes do poder público, lideranças comunitárias, entre outras. Tal concepção agrega à Comunicação Científica possibilidades interpretativas variadas sobre o público no contexto com a sociedade e organizações, o que permite considerar as suas dinâmicas como fatores intervenientes nos processos comunicacionais do campo científico, para garantir o alinhamento das proposições contextuais de Castells.

\section{Contribuições teóricas da noção de esfera pública em Arendt e Habermas}

A diversidade do público que compõe o fazer científico precisa ser pensada não somente pela sua composição, formada por diferentes instâncias e origens, mas, sobretudo pela atuação na esfera pública. Acreditamos que, para cumprir com os propósitos associados à cidadania e ao bem comum, a Comunicação Científica precisa estar ancorada em princípios relacionados à dialogicidade e participação, não sendo guiada por meio da lógica técnica e excludente do capital. Se o conceito de arena transepistêmica serve, entre outros fins, para evidenciar a pluralidade dos públicos com os quais o campo científico se relaciona, é preciso também pensar as formas por meio das quais esses públicos podem contribuir e participar da produção que daí emana, não isolando os sujeitos em polos de emissão e recepção de mensagens, conforme já problematizado acima.

Nessa perspectiva, ainda que de passagem, recorremos às proposições de Hannah Arendt e Habermas sobre a noção de esfera pública, para reafirmar algumas das suas potencialidades em ensejar modos de participação aplicáveis à valorização da dimensão política da Comunicação Científica. O pensamento desses autores compõe uma das possíveis perspectivas teórico-epistemológicas para a discussão que aqui se objetiva. Devido ao escopo do texto, também não evidenciaremos dissonâncias entre esses autores, tampouco maiores críticas às suas obras. 
Em uma das suas principais obras, A Condição Humana, Arendt (2015) atribui o declínio da esfera pública à guinada provocada por Galileu nas ciências e ao pensamento cartesiano na era moderna. Essas perspectivas científicas e filosóficas tiveram, pelo menos, dois efeitos observáveis: a crítica ao conhecimento como decorrência dos sentidos, logo, relacionada à vida contemplativa priorizada pela filosofia grega; a valorização da construção de artefatos que possibilitariam ao homem melhor explorar o mundo, via processos de mediação. No plano econômico, tais implicações foram aprofundadas pelo capitalismo com a priorização do trabalho, que gera bens duráveis, e com a retração do espaço público, como lugar de discussão e regulação social, que cedeu espaço ao privado enquanto lócus de atomização do homem voltado à produção material e à família.

Para compreender as razões pelas quais Arendt considera esse fenômeno algo problemático, é necessário retroceder, brevemente, a alguns dos seus conceitos. Primeiro, a era moderna enseja aquilo que ela denomina esfera social, a qual dilui as fronteiras entre público e privado e desabilita, portanto, as potencialidades da esfera pública como lugar da interação social via debate. De acordo com Arendt, três dimensões compõem a vita activa, o conjunto das atividades humanas que integram desde manuais até contemplativas: a) o labor, voltado para as atividades de subsistência, de manutenção básica da vida e que se encerra no seio familiar; b) o trabalho ou faber, referente à transformação de recursos da natureza e à produção de bens duráveis para permanência do homem, também atinente ao espaço privado; c) a ação ou práxis, própria ao espaço público por meio da qual os homens eternizam-se no exercício do que Aristóteles chama de dimensão pública do bios politikos (2004).

Ao realizar essa classificação, Arendt elege a Pólis grega como referência do exercício da ação. É na esfera pública que os homens, por meio do discurso ou léxis, discutem livremente, e materializam a participação, via retórica, viabilizada à medida que se tornam presentes as condições para o diálogo, a pluralidade e a igualdade. Assim sendo, Arendt rechaça a esfera privada como lugar de atuação política, uma vez que nela são exercidas formas de violência e dominação livres de quaisquer regulações da coletividade, inerentes à esfera pública. Também as características das atividades do labor e do trabalho não visam à perenidade, mas a sobrevivência e a manutenção de padrões que retiram do homem as condições do exercício pleno da práxis e da léxis.

De acordo com Arendt, é via ação e discurso que os humanos aparecem e tornam-se visíveis aos outros. Exclusividade dessa parte da vita activa, o discurso permite ao homem inserir-se publicamente, marcando a própria existência. Dessa forma, é por meio de palavras e atos que "nos inserimos no mundo humano, e essa inserção no mundo humano é como um segundo nascimento, no qual confirmamos e assumimos o fato simples do nosso aparecimento físico original”. (ARENDT, 2015, p. 219). A ação denota a sua relevância justamente porque "não apenas mantém a mais íntima relação com a parte pública do mundo comum a todos nós, mas é a única atividade que o constitui” (ARENDT, 2015, p. 245). 
Arendt reconhece na esfera pública a instância na qual se validam e se regulam opiniões mediante a comunicação intersubjetiva que põe em diálogo as diferentes perspectivas geradas na pluralidade.

\begin{abstract}
Na perspectiva daqueles que fazem a experiência da sociedade, é a pluralidade dos pontos de vista que confere certeza ao que existe, sem que essa certeza se desdobre numa identidade que anularia as diferenças sob o signo de uma única opinião. Essa pluralidade, portanto, faz apelo ao senso comum. Enquanto condição da comunicação intersubjetiva, constrói as referências e as evidências a partir das quais as experiências pessoais e subjetivas podem ser confirmadas na sua validade. (TELLES, 1990, p. 30).
\end{abstract}

Nesse aspecto reside a potencialidade política da ação e do discurso, pois, na coletividade ocorrem as mediações necessárias à efetivação da pluralidade e das condições amplas de participação. Esse entendimento tem implicações sobre a própria noção de poder para Arendt, que o entende de maneira diferente de dominação, como expressão de uma comunidade organizada politicamente para consolidar suas formas de participação e mudança social.

Enquanto Arendt declara que as transformações da modernidade geraram um declínio da esfera pública, Habermas situa tais alterações no que denomina Mudança Estrutural da Esfera Pública, título de uma das suas mais relevantes obras. O autor delimita o surgimento de uma esfera pública burguesa, constituída, inicialmente, na Inglaterra, entre os séculos XVII e XVIII, e, posteriormente, na França e Alemanha, como o fenômeno que possibilitou às pessoas privadas, reunidas em espaços públicos, como cafés, expressar suas opiniões, inclusive opondo-se ao poder absolutista e coletivizando a defesa dos interesses econômicos da classe burguesa. Esses interesses assentavam-se na preservação das atividades mercantis, debatidas em ambientes públicos por uma categoria que, progressivamente, passou a ter maior acesso a bens culturais e passou a construir juízos com base na crescente imprensa.

Genericamente, esse ambiente se tornou possível devido a algumas condições elencadas por Habermas: o próprio caráter público das discussões; a igualdade de condições para emitir opiniões; ter o mesmo poder de voz e crítica. Fundamentado no parâmetro metodológico de "tipo ideal”, concebido por Weber (2001), Habermas estabelece como pilares da esfera pública a liberdade de opinião, a legitimidade para emitir conceitos e a possibilidade de entes privados conversarem entre si como iguais livres de hierarquias (KOSSA, 2010). Habermas chama atenção para o seguinte fato, a esfera pública que analisa não deve ser generalizada como um modelo, não sendo retirada do seu contexto histórico, os princípios que a definem são condições ideais para a publicização e circulação livre das ideias, assumem, portanto, um caráter de orientação teleológica e não somente explicativa e heurística.

Habermas avança em relação a Arendt, ao considerar o papel dos meios de comunicação na constituição da esfera pública, evidenciando suas potencialidades. No entanto, enfatiza que, a partir do século XIX, com a massificação e a formação dos oligopólios da imprensa, esta se despolitiza enquanto 
forma de pautar e condicionar ambientes propícios à discussão. A política perde-se assim como finalidade de construção de um espaço público, constituindo o meio para a defesa de grupos segmentados com fins comerciais em uma lógica de crescente consolidação do capital.

Esse contexto marca o avanço de uma razão tecnocrática e instrumental, motivada pelos interesses do capital. Marca também o que Habermas denomina mundo sistêmico, materializado em subsistemas políticos e econômicos. Em oposição, está o mundo da vida, instância em que agentes comunicativos intercambiam livremente opiniões na formação de consensos, orientados por condições de igualdade de discussão e participação. Ao explicar esse aspecto presente na obra Teoria do Agir Comunicativo, Kossa afirma:

durante a ação comunicativa o sujeito faz uso do seu referencial objetivo, subjetivo e intersubjetivo. Sem isso, não há possibilidade de ocorrer ação comunicativa, pois o pressuposto objetivo (que diz respeito à suposta verdade do que é comunicado), o subjetivo (da veracidade) e o intersubjetivo (das condições normativas) é que dão a condição de tematização do mundo da vida (KOSSA, 2010, p. 25).

O agir comunicativo estabelece-se, assim, em situações linguísticas ideais que pressupõem “a participação de todos os interessados no discurso, tendo todos chances idênticas de argumentar, interpretar e refutar, e, de forma dialógica, colocar em relevo as coações que impedem o completo desenvolvimento de uma ação comunicativa." (CARVALHO, 2008, p. 46). Com isso, os participantes não devem ser movidos por coação, mas por vontade própria e livre para construírem integração social por meio de discursos e consensos.

Ao considerar o agir comunicativo uma oportunidade de construção de entendimentos discursivos abertos entre sujeitos capazes de falar e de agir, Habermas aproxima-se da concepção de Arendt e afirma: aqueles que agem comunicativamente referem-se a "não mais diretamente a algo no mundo objetivo, social ou subjetivo, mas relativizam suas enunciações diante da possibilidade de que a validade delas seja contestada por outros atores" (HABERMAS, 2012, p. 143).

O agir comunicativo e a construção de consensos daí decorrente não ocorrem livres de tensões, por isso, Habermas pontua:

Se é verdade que a integração social tem de ser garantida, cada vez mais, por via de um consenso a ser obtido por meio da comunicação, é necessário também, colocar o problema dos limites da capacidade integradora do agir orientado pelo entendimento e dos limites da eficácia empírica dos motivos racionais. Pois as pressões de reprodução inerentes ao sistema social, que perpassam as orientações da ação dos indivíduos socializados, não se abrem à análise das estruturas interacionais. (HABERMAS, 2012. p. 203). 
Com isso, Habermas evidencia que são constantes e intensas as forças inerentes aos subsistemas econômicos e políticos orientados a diminuir a esfera pública, e colonizar o mundo da vida, reduzindo seu potencial gerador de discussões e reconfigurando (restringindo) a formação de posicionamentos ao âmbito privado e de maior atomização do homem.

As relações entre as obras de Arendt e Habermas são densas e profundas, ainda mais quando aí se incluem as leituras e críticas deste à pensadora política. Desse modo, cabe-nos, por ora, destacar algumas contribuições sobre a noção de esfera pública em ambos, de modo a, sobretudo, demarcá-las como princípios a serem guiados pela Comunicação Científica na perspectiva da Comunicação Pública da Ciência. No nosso entendimento, esta deve estabelecer, conceitualmente, a sua atuação como síntese dialética entre a disseminação e a divulgação, portanto, pertencente a um contexto maior, qual seja o das arenas transepistêmicas.

\section{Comunicação Científica na perspectiva da Comunicação Pública da Ciência e os princípios da esfera pública}

Conceitualmente, a Comunicação Pública da Ciência diz respeito ao somatório das atividades que possuem conteúdos científicos elaborados de modo a ser acessível ao chamado "público leigo" (CARIBÉ, 2015). A sua atuação é estimulada por três fatores básicos, a saber:

a) o interesse e a curiosidade do público em obter informações acerca do que se produz em C\&T; b) a consciência de que os sistemas de C\&T mantenham a imagem da ciência como instrumento de bem-estar econômico e social, para que a opinião pública seja favorável ao desenvolvimento e financiamento de projetos; c) a imprescindibilidade da informação científica para a compreensão da realidade que cerca o homem moderno. (SILVEIRA, 2000 apud CARIBÉ, 2015, p. 100).

Por ter em vista categorias como o interesse público, a construção de imagens favoráveis e a formação de opinião pública, mesmo que para um fim bem tematizado na ciência, tecnologia, inovação e desenvolvimento, a Comunicação Pública da Ciência possui, subjacente, o conceito e os princípios da Comunicação Pública. Inicialmente, e para alguns autores, a Comunicação Pública é identificada, de maneira geral, como "comunicação governamental". No entanto, a ampliação do atual entendimento sobre o seu conceito produziu, entre diversos autores, algum consenso em relação a: a) sua abrangência e finalidade ligada voltada para toda a comunicação de interesse público, cuja maior interessada é a sociedade civil (OLIVEIRA, 2004; BRANDÃO, 2007; KUNSCH, 2012); e b) seus entes promotores, ligados “ao aparato estatal, às ações governamentais, a partidos políticos, ao Legislativo, ao Judiciário, ao 
terceiro setor, às instituições representativas, ao cidadão individualmente e, em certas circunstâncias, às ações privadas" (DUARTE, 2011, p. 126). Logo, diz respeito a diversas instituições cujo caráter da comunicação emitida é estrutural ou circunstancialmente público, dizendo respeito à sociedade em geral.

Na mesma direção de Brandão (2007), podemos delimitar diversos aspectos da Comunicação Pública, que figuram como premissas da Comunicação Pública da Ciência, tais como o acesso às informações de C,T\&I enquanto exercício de cidadania e o posicionamento da ciência em relação aos assuntos de ordem pública e das decisões políticas e econômicas, o que demanda tornar-se visível para ter legitimação social. Segundo Duarte (2007), essa concepção motivou a Comunicação Científica a adotar princípios como produzir o conhecimento sobre a sua existência, disponibilidade, oportunidade, acesso e linguagem adequada para que a sociedade se apropriasse dessas informações.

O alinhamento da Comunicação Pública da Ciência aos princípios da Comunicação Pública pode assumir diversas feições aproximando-se, mais ou menos, dos princípios da esfera pública preconizados por Arendt e Habermas. Tais possibilidades expressam-se em duas tendências da Comunicação Científica, segundo Fares, Navas e Marandino (2007): a unidirecional e a bidirecional. Na primeira, reside o modelo de déficit que supõe um público passivo e sem conhecimento que recebe, unidirecionalmente, informações dos cientistas que detêm o saber objetivo e legitimado. Ainda nessa direção, existe o modelo contextual, que parte do mesmo princípio, mas considera aspectos sociais e psicológicos do receptor. Em uma perspectiva dialógica, estão os modelos da experiência leiga, em que os conhecimentos locais podem ocupar a mesma importância do conhecimento científico; e o da participação pública e democrática, por meio do qual os não cientistas atuam nos assuntos e políticas do campo de relações formado entre a ciência, a tecnologia e a sociedade.

Nesse sentido, a Comunicação Pública da Ciência cujo fim é um modelo participativo e democrático, se alinha a uma das principais referências teóricas da área da Comunicação Pública, a saber, Zémor (1995), que reforça a tese de que esta deve estar intrinsicamente ligada às finalidades das suas instituições: a) informar, levando ao conhecimento, prestar contas e valorizar; b) ouvir as demandas, expectativas e questionamentos; c) contribuir para a relação social, favorecendo a coletividade e a cidadania e d) acompanhar as mudanças comportamentais e de organização social. A perspectiva de Zémor reforça que a Comunicação Pública esteja imbuída de "uma exigência de um espírito eminentemente público como o norteador das ações pragmáticas de difusão de mensagens, de atendimento ao cidadão e de elaboração de políticas públicas a partir do interesse coletivo" (NOBRE e GIL, 2013, p. 15).

Resguardadas as diferenças filosóficas e conceituais, Arendt e Habermas estabelecem como premissas de efetividade da esfera pública, enquanto instância de participação: a pluralidade; a interação dos sujeitos por meio de trocas intersubjetivas; a defesa de condições que assegurem poder de fala, posicionamento e crítica; atuação coletiva na formação de consensos e a discussão como forma de ampliar 
a atuação pública nos destinos comuns. Esses princípios balizam teoricamente o campo da Comunicação Pública ao situar como pressupostos o interesse público, a transparência, o diálogo e a postura ética e responsiva.

A noção de esfera pública estabelece, assim, as condições ideais para o desenvolvimento pleno da Comunicação Pública. Zémor (1995) reafirma essa perspectiva e declara que esta deve responder a quatro exigências: 1) informar, por dever, de forma ética e transparente; 2) assegurar a pedagogia para transmitir mensagens em diferentes níveis de complexidade; 3 ) incluir a comunicação no processo de identificação e deliberação e 4) contribuir para restituir o sentido de vida coletiva.

Essas exigências requerem considerar a Comunicação Científica como síntese dialética por meio da qual se contemplam, ao mesmo tempo, atividades ligadas à disseminação e à divulgação. De modo a aprofundar suas implicações, não se trata somente de transmitir, tendo em vista especialistas e "público leigo", mas ensejar a participação ampla de todos, desde a concepção das ideias da C,T\&I na construção de uma ciência de base contextual. Isso significa, em primeiro lugar, garantir as condições de igualdade dos participantes nas discussões, o que exige reflexão e ação, no sentido arendtiano, para destituir as hierarquias que forjam concepções sobre os conhecimentos e que resvalam no prejuízo da participação ampla e irrestrita.

A aplicação dos princípios que formam a esfera pública por parte Comunicação Científica, na perspectiva da Comunicação Pública da Ciência, requer também o reconhecimento das diferenças, considerando a pluralidade constitutiva das arenas transepistêmicas. Nesse ponto, é importante recordar a observação habermasiana de que a sociedade deve ser vista, concomitantemente, como um mundo sistêmico e mundo da vida, em constante tensão. Não é, destarte, aleatória a terminologia arena para se referir às comunidades do campo científico, uma vez que neste, diversos interesses, de ordens muitas vezes a-científicos, apresentam-se em constante conflito para sobreporem-se uns aos outros. Faz sentido, por fim, apenas pontuar uma crítica importante ao pensamento de Arendt, a de que a política tende a ser vista, em sua obra, autonomizada pela ação e pelo discurso e como instância de exercício do poder enquanto potência de participação dos sujeitos que se opõem à dominação, como categoria conceitual relegada apenas ao campo da economia. Isso, porque conforme indicamos anteriormente, o contexto, como unidade de análise, deve contemplar às variáveis sociais, políticas, econômicas, entre outras, de modo relacional, para definir, inclusive, as melhores formas de engendrar uma Comunicação Científica implicada com o bem comum e assertivamente pública da ciência.

\section{Considerações finais}

Uma das consequências do trabalho da Comunicação Científica termina por ser a formação de imagens favoráveis da $\mathrm{C}$,T\&I que justifiquem a necessidade da sua existência enquanto pré-requisito 
propulsor de desenvolvimento econômico e social. Essas imagens não devem estar assentadas em crenças que alcem a C,T\&I ao plano da inacessibilidade e do esoterismo, mas deve ser calcada pelo crença do ciência como bem público, portanto, implicada e aberta a fazer-se entender como conjunção de variáveis de diversas naturezas. A principal força interveniente nesse processo precisa ser os diversos sujeitos que participam, de modo direto ou não, do fazer científico. Trata-se, assim, de uma motivação de ordem ética e política que supere a razão tecnocrática, fundante do modo de produção capitalista, que encerra as possibilidades de atuação dos sujeitos enquanto agentes comunicativos na esfera pública.

A forma mais estrutural de efetivar essa perspectiva é reforçar a articulação indissociável entre a ciência e a educação. Por mais óbvio que tal aproximação pareça, o campo da educação científica, da qual emanam nomenclaturas como alfabetização científica, compreensão pública da ciência, entre outras, ainda padece de parâmetros para que diversas camadas da sociedade percebam a C,T\&I como elemento inerente ao seu cotidiano e como um bem público por meio do qual também podem ocorrer a articulação coletiva e o exercício do poder, nos termos de Arendt.

Nessa direção, segundo Caldas (2010):

Considerando que quase tudo que acontece na sociedade é influenciado pela $C \& T$, é preciso que o discurso científico seja amplamente compreendido pela população, para que possa tomar suas decisões a partir de múltiplas informações, considerando os aspectos positivos e negativos de cada situação. Não se trata, obviamente, de negar a especificidade dos saberes, nem de abrir mão deles, mas, sim, de possibilitar a participação efetiva da sociedade em debates públicos sobre temas polêmicos, como transgênicos, biotecnologia, energia nuclear, entre tantos outros, cujos impactos sociais são inegáveis. (CALDAS, 2010, p.33).

Sintonizado com a perspectiva contextual do fazer científico, Bueno (2013) também afirma que a Comunicação Pública da Ciência precisa compreender que a sua atuação está diretamente relacionada às controvérsias sociais, as quais refletem complexas relações de poder e, por isso, não podem ser vistas como resultantes de processos de desenvolvimento técnico, mas como construção histórica. Desse modo, a adoção de modelos e formatos comunicacionais refere-se a escolhas emanadas do jogo de disputas e tensões advindas das arenas transepistêmicas que se inter-relacionam nas mediações de sujeitos e instituições.

Ressignificar a Comunicação Científica como síntese dialética dos processos de disseminação e divulgação pode ser, portanto, um passo para transcender a sua visão como uma atividade que se divide para atender a um público ou outro, ou a ambos, em tempos diferenciados. Claro que as distinções relacionadas aos formatos de comunicação devem se aperfeiçoar, mas no sentido de potencializar seus processos dialógicos e não como forma de reafirmar a hierarquia do conhecimento científico por meio do hermetismo linguístico, por exemplo. Trata-se, portanto, "não só de divulgar a produção da ciência, mas de possibilitar a apreensão desse conhecimento, para que o público em geral possa não apenas 
compreender seus processos, mas também participar de decisões sobre temas de interesse da sociedade." (CALDAS, 2014, p. 5).

Os princípios apontados por Arendt e Habermas, ainda que utópicos, servem para manter a concepção teleológica da esfera pública, cuja fisionomia conceitual alimenta outras noções, como a de Comunicação Pública e de Comunicação Pública da Ciência. Nesses, em coerência com a discussão aqui tecida, as próprias formas de participação dos sujeitos no fazer ciência devem ser definidos pelos próprios, o que os desloca da condição de receptores passivos de informação. $\mathrm{Na}$ atual conjuntura do Estado brasileiro, torna-se imperativo manter esses princípios, bem como postura crítica, para assegurar liberdade de opinião, de voz e de todas as condições para o exercício da pluralidade de pensamentos de forma a fazer a C,T\&I refletir os anseios e inquietações sociais, efetivando-se como instância contextual de resolução das demandas que daí emanam.

\section{Referências}

ARENDT, Hannah. A Condição Humana. Rio de Janeiro: Forense Universitária, 2015.

ARISTÓTELES. Política. São Paulo: Martins Claret, 2004.

BERNAL, John D. The social function of science. London: George Routledge \& Sons, 1939.

BOURDIEU, Pierre. Os usos sociais da ciência: por uma sociologia clínica do campo científico. São Paulo: Editora UNESP, 2004.

BRANDÃO, Elizabeth Pazito. Conceito de Comunicação Pública. In: DUARTE, Jorge. Comunicação Pública: Estado, Mercado, Sociedade e Interesse Público. São Paulo: Atlas, 2007.

BUENO, Wilson Costa. Comunicação cientifica e divulgação científica: aproximações e rupturas conceituaiss. Informação \& Informação, v. 15, n. 1esp, p. 1, 15 dez. 2010.

BUENO, Wilson Costa. Jornalismo científico no Brasil: os compromissos de uma prática dependente. 1984, 364f. Tese (Doutorado)-Escola de Comunicação e Artes, USP, 1984. 
BUENO, Wilson da Costa. Jornalismo científico: revisitando o conceito. In: VICTOR, C.; CALDAS, G.; BORTOLIERO, S. (Org.). Jornalismo científico e desenvolvimento sustentável. São Paulo: All Print, 2009. p.157-178.

BUENO, Wilson da Costa. Opinião: ciência, tecnologia e poder: o papel do jornalismo científi co. Portal Imprensa. 24/04/2013. Disponível em: <http://portalimprensa.uol.com. $\mathrm{br} /$ noticias/wilson $+\mathrm{da}+$ costa + bueno/58250/opiniao $+\quad$ ciencia + tecnologia $+\mathrm{e}+$ poder $+\mathrm{o}+$ papel $+\mathrm{d}$ o+jornalismo+cientifi co >. Acesso em: 1 jul. 2019.

CALDAS, Graça. Divulgação científica e relações de poder. Informação e Informação, Londrina, v.15, n. $\quad$ esp. $\quad$ p. 31-42, 2010.2 Disponível em: $<$ http://www.uel.br/revistas/uel/index.php/informacao/article/view/5583/6763>. Acesso em: 1 jul. 2019.

CARIBÉ, Rita de Cássia do Vale. Comunicação Científica: reflexões sobre o conceito. Informacao \& Sociedade-Estudos, v. 25, n. 3, p. 89-104, 2015

CARVALHO, Lucas Correia. Esfera pública e esfera privada: uma comparação entre Hannah Arendt e Jürgen Habermas. Revista Habitus: revista eletrônica dos alunos de graduação em Ciências Sociais IFCS/UFRJ, Rio de Janeiro, v. 6, n. 1, p. 38-52, dez. 2008. Se- mestral. Disponível em: $<$ www.habitus.ifcs.ufrj.br>. Acesso em: 1 jul. 2019.

CASTELLS, Manuel. A sociedade em rede. São Paulo: Paz e Terra, 2016.

DUARTE, Jorge. Sobre a emergência do(s) conceito(s) de comunicação pública. In: KUNSCH, Margarida Maria Krohling (Org.). Comunicação Pública, Sociedade e Cidadania. São Caetano do Sul, SP: Difusão Editora, 2011.

FARES, D. C.; NAVAS, A. M.; MARANDINO, M. Qual a participação? Um enfoque CTS sobre os modelos de comunicação pública da ciência nos museus de ciência e tecnologia. In: REUNIÃO DA REDE DE POPULARIZAÇÃO DA CIÊNCIA E TECNOLOGIA NA AMÉRICA LATINA E CARIBE, 10., 2007. San José, Costa Rica. Anais. São José, Costa Rica, 2007.

HABERMAS, Jurgen. Mudança Estrutural da Esfera Pública: investigações quanto a uma categoria da sociedade burguesa. Rio de Janeiro, Tempo Brasileiro, 2003. 
HABERMAS, Jurgen. Teoria do Agir Comunicativo: sobre a crítica da razão funcionalista. Vol. 2. São Paulo: Editora WMF Martins Fontes, 2012.

HOUAISS, Antônio. Dicionário Houaiss da Língua Portuguesa. Rio de Janeiro, Ed. Objetiva, 2010.

KNORR CETINA, Karin. ¿Comunidades científicas o arenas transepistémicas de investigación? Una crítica de los modelos cuasi-económicos de la ciencia. Redes, v. 3, n. 7, p. 129-160, 1996.

KNORR CETINA, Karin. La Fabricación del conocimiento: um ensaio sobre el carácter constructivista y contextual de la ciencia. Bernal: Universidad Nacional de Quilmes, 2005.

KOSSA, Pablo. Caminhos para a Comunicação Pública: a rádio universitária como estudo de caso. 2010. 125 f. Dissertação (Mestrado). Programa de Pós-Graduação em Comunicação da Faculdade de Comunicação e Biblioteconomia da Universidade Federal de Goiás, Universidade Federal da Goiânia, 2010.

KUNSCH, Margarida Maria Krohling. Comunicação Pública: direitos de cidadania, fundamentos e práticas. In: MATOS, Heloiza Helena Gomes de (Org.). Comunicação Pública: interlocuções, interlocutores e perspectivas. São Paulo: ECA/USP, 2012.

LEITE, Fernando C. Lima. Gestão do conhecimento científico no contexto acadêmico: proposta de um modelo conceitual. Brasília, 2006. 240p. Dissertação (Mestrado em Ciência da Informação) Programa de Pós-Graduação em Ciência da Informação, Universidade de Brasília.

MARTINO, Luiz. C. De qual comunicação estamos falando? In. HOHLFELDT, Antonio; MARTINO, Luiz C. FRANÇA, Vera Veiga. Teorias da Comunicação: conceitos, escolas e tendências. Petrópolis, RJ: Vozes, 2010.

MEADOWS, A. J. A comunicação científica. Brasília: Briquet de Lemos, 1999.

NOBRE, Heloiza Helena Matos e; GIL, Patrícia. Alternativas ao conceito e à prática da comunicação pública. In: Revista Eletrônica Internacional de Economia Política da Informação e da Cultura: Eptic On line. São Paulo, V. 15, $\mathrm{n}^{\circ}$ 2. 2013. Disponível em: https://seer.ufs.br/index.php/eptic/article/view/937. Acesso em: 02 nov. 2017. 
OLIVEIRA, Maria José da Costa. Comunicação Pública e os Setores Não-Estatais. In: OLIVEIRA, Maria José da Costa (Org.). Comunicação Pública. Campinas, SP: Alínea, 2004.

SILVEIRA, T. S. Divulgação e Política Científica: do bar do mané à Ciência Hoje (1982 - 1998). $210 f$. 2000. Dissertação (Mestrado)-Instituto de Geociências, UNICAMP, 2000.

TAKEUCHI, Hirotaka; NONAKA, Ikujiro. Gestão do Conhecimento. Porto Alegre: Bookman, 2008.

TELLES, Vera da Silva. ESPAÇO PÚBLICO E ESPAÇO PRIVADO NA CONSTITUIÇÃO DO SOCIAL: notas sobre o pensamento de Hannah Arendt. Tempo social, São Paulo , v. 2, n. 1, p. 23 48,1990 . Disponível em <http://www.scielo.br/scielo.php?script=sci_arttext\&pid=S010320701990000100023\&lng=en\&nrm=iso $>$. Acesso em 20 jun. 2019.

WEBER, Max. Metodologia das Ciências Sociais. Parte 1. São Paulo: Cortez e Editora Unicamp, 2001.

ZÉMOR, Pierre. La Communication Publique. Paris: PUF, 1995. 